\title{
Opioid analgesia on the battlefield: a retrospective review of data from Operation HERRICK
}

\author{
Pip Lewis, ${ }^{1,2}$ C Wright, $^{1,2}$ C Hooper $^{3}$
}

${ }^{1}$ Emergency Department, Imperial College Healthcare NHS Trust, London, UK ${ }^{2}$ Academic Department of Military Emergency Medicine, Royal Centre for Defence Medicine, Birmingham, UK ${ }^{3} 1700$ Naval Air Squadron, RNAS Culdrose, Cornwall, UK

\section{Correspondence to} Pip Lewis, Emergency Department, Imperial College Healthcare NHS Trust, London W21NY, UK; pip.lewis1@nhs. net

Received 10 December 2017 Revised 13 March 2018 Accepted 14 March 2018 Published Online First 6 April 2018
Check for updates

To cite: Lewis $P$, Wright $C$, Hooper C.

J R Army Med Corps

2018;164:328-331.

\begin{abstract}
Background Acute pain secondary to trauma is commonly encountered on the battlefield. The use of morphine to manage pain during combat has been well established since the 19th century. Despite this, there is relatively little research on analgesia use in this environment. This study aims to review the use and complications of morphine and other opioids during Operation HERRICK. Methods A database search of the Joint Theatre Trauma Registry was completed looking for all incidences of morphine, fentanyl or naloxone use from February 2007 to September 2014. Microsoft Excel was used to analyse the results.
\end{abstract}

Results Opioid analgesia was administered to 5801 casualties. Morphine was administered 6742 times to 3808 patients. Fentanyl was administered 9672 times to 4318 patients. Naloxone was used 18 times on 14 patients, giving a complication rate of $0.24 \%$. Opioid doses prior to naloxone administration range from 0 to $72 \mathrm{mg}$ of morphine and from 0 to $100 \mathrm{mcg}$ of fentanyl. Four casualties (two local civilians and two coalition forces) received naloxone despite no recorded opioids being administered. Opium abuse was prevalent among the local population in Afghanistan, and this could explain the rationale behind two local national casualties receiving naloxone without any documented opioids being given.

Conclusion The use of opioids in a battlefield environment is extremely safe. Complication rates are similar to previously published data which is reassuring. The efficacy of different opioids was not covered by this study, and further analysis is required, particularly following the introduction of oral transmucosal fentanyl citrate and the availability of novel non-opioid analgesics.

\section{INTRODUCTION}

On the battlefield, acute pain, particularly secondary to trauma, is commonly encountered and requires treatment with analgesia in the prehospital, evacuation ('en-route') and hospital setting. Ineffective management of pain has both short and long-term consequences for the casualty, and it is a challenge to achieve the correct balance of relieving pain without exacerbating any haemodynamic instability casualties have as a result of trauma. The development of chronic pain conditions and increased rates of post-traumatic stress disorder have been shown to be related to inadequate analgesia use during combat. ${ }^{1-4}$

The ideal pain regimen for treating casualties has yet to be established. ${ }^{5}$ The individual response to any one type of analgesia is varied, with some patients experiencing relief and others unpleasant side effects. The ideal analgesic should have rapid onset

\section{Key messages}

The use of opioid analgesia to manage pain on the battlefield has been well established since the 19th century.

- Of the 5801 patients in this study who received morphine, fentanyl or both, $0.24 \%$ had narcosis requiring the use of naloxone.

- Further research is required, however, in order to find the most effective analgesic agent for our casualties.

and few side effects. It should be administered via various routes, as intravenous access is potentially challenging in the peripherally shutdown trauma patient. It should also have the unique quality of being able to be self-administered, in order to allow casualties to manage their own pain should medical support not be immediately available.

The use of morphine and other opioids to manage pain during combat has been well established since the 19 th century, ${ }^{6}$ and it does possess many of the characteristics described above. It is not without complications, and is known to cause a classic toxidrome of respiratory depression, miosis and decreased conscious level. ${ }^{7}$ During World War II there were reports of deaths due to the delayed onset of the effects of intramuscular morphine when given to cold or hypovolaemic casualties. ${ }^{8}$ Naloxone, the antidote for opioid overdose, is a competitive mu-opioid receptor antagonist that reverses all signs of opioid intoxication ${ }^{9}$ and has been used widely for the management of opioid overdose since the 1970s. It is safe and effective, and has little effect on the patient if they have no opioid in their system.

More recently, the UK military has introduced fentanyl as an alternative opioid analgesic, both in intravenous and oral forms. Oral transmucosal fentanyl citrate (OTFC) was originally licensed for use as pain relief for palliative care patients, but has been adopted by the military as a safe and effective alternative to morphine. ${ }^{1011}$

Despite the popularity and widespread use of morphine and other opioid analgesics, there are relatively few studies reviewing the use and safety of analgesia during conflict. The objective of this study was to review the use of and complications from opioid analgesics in a combat environment.

\section{METHODS}

The Joint Theatre Trauma Registry (JTTR) is a database of all trauma patients, both military and 
civilian, treated by Defence Medical Services (DMS) at deployed hospital facilities during recent conflicts. Data on all patients who trigger trauma team activation have been collected since the beginning of the Iraq conflict in 2003 and the data set is maintained by the Academic Department of Military Emergency Medicine (ADMEM).

Following permission being granted by ADMEM, a database search of JTTR was carried out looking for all the incidences of administration of either morphine, fentanyl or naloxone from February 2007 to September 2014. An individual episode was ascribed when a patient received a dose of analgesia (ie, initial drug administration, a subsequent different drug or the same drug via an alternative route).

Routes of administration were defined as intravenous, intramuscular, transmucosal, intraosseous and oral. Other data captured concerned: dose of drug delivered, location of drug administration (either at Role 1, during evacuation of the casualty or at the Role 3 deployed hospital facility), demographics, injuries sustained and Injury Severity Score (ISS) for the patients who received naloxone. Microsoft Excel was then used to analyse the data set and perform descriptive statistics on the data retrieved. Categorical data are reported as percentages and skewed data reported using median and IQRs.

\section{RESULTS}

During the 7-year period of conflict a total of 6942 patients were recorded onto the JTTR database, of which opioid analgesia was administered to 5801 (83.5\%). Morphine was administered a total of 6742 times to 3808 patients (1.77 times per casualty). Morphine was administered more often in Role 3 (56.1\%) than in prehospital environments. The median dose patients received was $10 \mathrm{mg}\left(\mathrm{IQR}_{25-75} 6-20 \mathrm{mg}\right)$ of morphine. It was given intravenously 5464 times, predominately at Role 3 (66.8\%); via the intraosseous route 151 times mainly during evacuation (74.2\%); and 953 times by intramuscular injection most commonly at Role 1 (90.2\%).

Fentanyl was administered a total of 9672 times to 4318 patients (2.24 times per casualty), mostly at Role 3 (81.8\%). Again, intravenous was the most common route of administration $(95.5 \%)$. Up to 258 episodes of OTFC use were recorded for 249 casualties, the majority of these during evacuation $(n=186)$ or at Role $1(n=67)$. Note that transmucosal administration of fentanyl requires much higher doses (typically $400-800 \mathrm{mcg}$ ) due to the 'first-pass effect' through the liver as a proportion of the drug will inevitably be ingested. This had the potential to skew the average dose of fentanyl received in these two environments and therefore doses of intravenous and OTFC were analysed separately. Median doses were 100 and $800 \mathrm{mcg}$, respectively (Tables 1 and 2). 46.2\% of all casualties during this time period received opioid analgesia in a pre-hospital environment.

Naloxone was administered 18 times to 14 separate patients, giving a complication rate of $0.24 \%$. The average age of patients
Table 2 Drug episodes by location

\begin{tabular}{llll}
\hline & $\begin{array}{l}\text { Role } 1 \\
\% \text { (n/total episodes) }\end{array}$ & $\begin{array}{l}\text { Evacuation } \\
\%(\mathbf{n} / \text { total episodes) }\end{array}$ & $\begin{array}{l}\text { Role } 3 \\
\%(\mathbf{n} / \text { total } \\
\text { episodes) }\end{array}$ \\
\hline Morphine & $27.8(1877 / 6742)$ & $16.1(1086 / 6742)$ & $56.1(3779 / 6742)$ \\
Fentanyl & $9.5(916 / 9672)$ & $8.7(842 / 9672)$ & $81.8(7912 / 9672)$ \\
OTFC & $30.0(67 / 258)$ & $72.1(186 / 258)$ & $1.9(5 / 258)$ \\
\hline
\end{tabular}

OTFC, oral transmucosal fentanyl citrate.

receiving naloxone was 22.6 years (4-45 years) and the average ISS was $14(1-50)$.

Of the 14 patients, six received naloxone at Role 1 , and eight at Role 3. Casualties were a mix of local civilians $(n=6)$, coalition military $(n=5)$ and UK military $(n=3)$. Mechanism of injury was as expected for the nature of the HERRICK conflict, with explosives being the single greatest cause of injury $(n=6)$. The remainder of casualties were injured by road traffic collisions $(n=5)$, gunshot wounds $(n=1)$, blast $(n=1)$ or burns $(n=1)$. The range of total morphine dose prior to the administration of naloxone is wide: between 0 and $72 \mathrm{mg}$ of morphine (median $10 \mathrm{mg}$ ). One casualty received $100 \mathrm{mcg}$ of fentanyl prior to naloxone and one other received both morphine and fentanyl prior to naloxone administration; a local civilian who received $10 \mathrm{mg}$ intravenous morphine at Role 1 and $25 \mathrm{mcg}$ intravenous fentanyl during evacuation. Two casualties were recorded as receiving 300 and $350 \mathrm{mcg}$ fentanyl, respectively, at Role 3 as well as naloxone, but it is not possible to work out from the data the timeline of drug administration. These casualties both received anaesthetic drugs at Role 3 , and therefore it is possible the fentanyl they received was as part of a rapid sequence induction (Table 3).

Four casualties received naloxone despite no recorded opioids being given. Two of these casualties were local civilians and the other two were coalition military. Opium and heroin abuse was prevalent among the local population in Afghanistan at the time, ${ }^{12} 13$ and therefore this could explain the rationale behind the two local national casualties receiving naloxone without any documented opioids being given. This does not account for the other two casualties.

\section{DISCUSSION}

In this study of 5801 patients receiving morphine, fentanyl or both, $0.24 \%$ had narcosis requiring the use of naloxone. These casualties were most likely to be local civilians, who had received between 0 and $10 \mathrm{mg}$ intravenous morphine or between 0 and $100 \mathrm{mcg}$ intravenous fentanyl prior to naloxone administration. Naloxone was more commonly used in a deployed hospital environment rather than in a prehospital care setting.

Comparisons to other data on analgesia use from combat environments are difficult due to the scarcity of available research. A systematic review of prehospital analgesia use, published in

Table 1 Drug episodes by route of administration and average dose

\begin{tabular}{lllllllll}
\hline Drug episodes & Intravenous & Intraosseous & Intramuscular & Transmucosal & Oral & Unknown & Other & Dose Median (IQR 25-75 $)$ \\
\hline Morphine & 5464 & 151 & 953 & - & 18 & 73 & $68^{*}$ & $10 \mathrm{mg}(6-20)$ \\
Fentanyl & 9234 & 137 & 12 & - & - & 41 & $248 \dagger$ & $100 \mathrm{mcg}(50-200)$ \\
OTFC & - & - & - & 258 & - & - & - & $800 \mathrm{mcg}(800-800)$ \\
\hline
\end{tabular}

*Infusion, nerve block, epidural, patient-controlled analgesia (PCA), intranasal.

†Bolus, epidural, infusion, intranasal, subcutaneous, nerve block.

OTFC, oral transmucosal fentanyl citrate. 
Table 3 Casualties who received naloxone

\begin{tabular}{|c|c|c|c|c|}
\hline $\begin{array}{l}\text { Naloxone } \\
\text { location }\end{array}$ & Opioids prior to naloxone & Type & Mechanism of injury & Injuries \\
\hline R1 & $10 \mathrm{mg}$ morphine intravenous & Coalition military & Explosive, mine & Scalp laceration and laceration to left forearm \\
\hline $\mathrm{R} 1$ & $10 \mathrm{mg}$ morphine intravenous & Local civilian & Explosive, IED & $\begin{array}{l}\text { Traumatic amputation right foot } \\
\text { Bilateral femoral fractures } \\
\text { Pelvic fracture } \\
\text { Traumatic amputation right hand }\end{array}$ \\
\hline R1 & $\begin{array}{l}20 \mathrm{mg} \text { morphine intramuscular } \\
14 \mathrm{mg} \text { morphine intravenous }\end{array}$ & UK military & Explosive, IED & $\begin{array}{l}\text { Traumatic amputation left below knee } \\
\text { Penile laceration } \\
\text { Calcaneal fracture right }\end{array}$ \\
\hline $\mathrm{R} 1$ & 100 mcg fentanyl intravenous & Local civilian & MVC & $\begin{array}{l}\text { Temporal fracture + extradural haematoma } \\
\text { Pelvic fracture } \\
\text { Blast lung }\end{array}$ \\
\hline R1 & - & Coalition military & GSW & Femoral artery and vein laceration \\
\hline R1 & - & Coalition military & MVC & $\begin{array}{l}\text { Right tibial plateau fracture } \\
\text { Neck laceration }\end{array}$ \\
\hline R3 & $5 \mathrm{mg}$ morphine intravenous & Local civilian & Explosive, mortar & Lung contusion and open wounds to left chest wall \\
\hline R3 & - & Coalition military & MVC & $\begin{array}{l}\text { Left humeral fracture } \\
\text { Pelvic fracture } \\
\text { Bilateral tibial fractures with vascular injury }\end{array}$ \\
\hline R3 & $10 \mathrm{mg}$ morphine intravenous & UK military & Crush & Crush injuries left forearm + compartment syndrome \\
\hline R3 & $\begin{array}{l}10 \mathrm{mg} \text { morphine intravenous } \\
25 \mathrm{mcg} \text { fentanyl intravenous }\end{array}$ & Local civilian & Explosive, IED & $\begin{array}{l}\text { Left open tib-fib fracture } \\
\text { Right closed tib-fib fracture } \\
\text { Calcaneal fracture }\end{array}$ \\
\hline R3 & - & Local civilian & MVC & $\begin{array}{l}\text { Left humerus fracture } \\
\text { Fractures T12-L4 }\end{array}$ \\
\hline R3 & Unclear & Local civilian & MVC & $\begin{array}{l}\text { Distal radius fracture } \\
\text { Left haemothorax } \\
\text { Pelvic fracture } \\
\text { Splenic laceration }\end{array}$ \\
\hline R3 & 72 mg morphine intravenous & UK military & Burn & Burns right hand partial and full thickness \\
\hline R3 & Unclear & Coalition military & Explosive, IED & Penetrating neck wound \\
\hline
\end{tabular}

GSW, gunshot wound; IED, improvised explosive device; MVC, motor vehicle collision; R1, Role 1; R3, Role 3; tib-fib, tibia and fibula.

$2010,{ }^{14}$ looked at 21 studies-three of which were of military casualties-found that of 3061 casualties receiving opioid analgesia $0.1 \%$ required naloxone. Two further studies reviewing prehospital analgesia by Israeli Defence Force medical providers and US medics describe no complications from any of the analgesia administered. ${ }^{15} 16$ A recently published review of US MEDEVAC key performance indicators ${ }^{17}$ found $0.2 \%$ of casualties required naloxone following opioid analgesia.

Up to 256 casualties in this series received OTFC, none of which required naloxone to manage side effects. Karlsen et $a l^{18}$ reviewed the use of OTFC in 286 US Army Special Operations Command casualties during combat deployments in Iraq and Afghanistan from March 2003 to March 2010. They recorded one adverse event-a patient received $3200 \mathrm{mcg}$ oral transmucosal fentanyl and $20 \mathrm{mg}$ intravenous morphine causing hypoventilation and desaturation requiring naloxone. The authors commented that this adverse event occurred in 2003 when OTFC was first used on the battlefield and no other major adverse event has been reported since that case. The largest doses of OTFC and morphine any of the casualties in our data set received were $1600 \mathrm{mcg}$ fentanyl and $10 \mathrm{mg}$ intravenous morphine.

$46.2 \%$ of casualties who received opioid analgesia did so prior to arriving at the Role 3 deployed hospital. The number of casualties receiving analgesia in the prehospital environment varies significantly in previously published literature from $12.3 \%$ to 100\%. ${ }^{151619}$ Like our study, the paper by Benov et al ${ }^{15}$ —which reports only $12.3 \%$ of casualties receiving analgesia in a prehospital environment-is a retrospective review and therefore likely to be subject to comparable challenges of data recording in a combat environment. It is likely that further prospective studies are required to fully discern how many of our casualties are actually receiving analgesia.

This study demonstrates that the administration of opioids in a combat setting is safe, with an extremely low complication rate. However, the data retrieved can only comment on the most serious complication of opioid use-respiratory depression. JTTR does not record data concerning other, more common but less severe, side effects of opioids such as nausea and vomiting or pruritus. It also does not record patients' reported pain scores, and therefore cannot comment on how effective the use of morphine and fentanyl are in actually managing pain in military trauma casualties. In fact, there are some studies suggesting that pain is poorly managed in this environment ${ }^{52021}$ and therefore further work may be required to improve our management of pain for these casualties.

Other available research from other militaries focuses on general analgesia use during combat, rather than specifically on opioids and its complications. Studies of US military practice show a propensity away from morphine use, towards fentanyl and ketamine, with good analgesic effect and few side effects. ${ }^{16-19}$ The predominant use of ketamine differs from current UK military practice, as only medical officers can administer ketamine and many general practitioners and General Duties Medical Officers are unfamiliar with its use, ${ }^{22}$ hence it is mainly restricted to use by practitioners on the Medical Emergency Response Team and in deployed hospital environments. 


\section{LIMITATIONS}

There are several limitations of this study. JTTR is an extremely valuable source of information and data from recent conflicts; however, some data may be missed. Though the database has been accessed retrospectively, the data capture is recorded prospectively by specialist trauma nurse coordinators to ensure the accuracy of information recorded. There were challenges when reviewing the doses of drugs given-both fentanyl and naloxone doses were inconsistently recorded either in micrograms or milligrams. There were two coalition casualties who received naloxone with no recorded opioids being given, which highlights the challenge of recording data consistently in a battlefield environment.

As previously mentioned, the data can only comment on the incidence of respiratory depression requiring naloxone use, it does not include the incidence of other less serious complications of morphine use, as well as not being able to comment on the effectiveness of morphine as an analgesic in these casualties. Nor were non-opioid analgesics considered in this review.

This data set reports that just under half of all casualties received opioid analgesia in the prehospital environment. All UK soldiers deployed on operations in Afghanistan carried and were trained to self-administer intravenous autoinjectors containing $10 \mathrm{mg}$ morphine. It is likely that the self-administration of intravenous morphine has not been fully captured in the data set, and the number of casualties receiving morphine at point of injury or in the prehospital environment is much higher than stated.

\section{CONCLUSION}

This is the largest study to date reviewing opioid analgesia use in a combat environment. We demonstrate that the use of opioids in a battlefield environment is extremely safe, with very few incidences of complications requiring the use of naloxone. Complication rates are similar to previously published research. Further research is needed following the introduction of OTFC by the DMS, and the availability of novel non-opioid analgesic alternatives.

Contributors The study was conceived by CW. Literature searches were carried out by PL. Data analysis and interpretation was carried out by PL and $\mathrm{CH}$. The first draft was written by $\mathrm{PL}$ and subsequent revisions were made by $\mathrm{PL}$ and $\mathrm{CW}$.

Funding This research received no specific grant from any funding agency in the public, commercial or not-for-profit sectors.

Competing interests None declared.

Patient consent Not required.

Provenance and peer review Not commissioned; externally peer reviewed.

Data sharing statement Data for this article were accessed from the Joint Theatre Trauma Registry (JTTR-UK), which is a database of all trauma patients treated by the Defence Medical Services in Iraq and Afghanistan. Access is necessarily restricted as it contains both confidential medical details and military operationally sensitive information, therefore permission would need to be sought in order to access the original data.

(c) Article author(s) (or their employer(s) unless otherwise stated in the text of the article) 2018. All rights reserved. No commercial use is permitted unless otherwise expressly granted.

\section{REFERENCES}

1 Holbrook TL, Galarneau MR, Dye JL, et al. Morphine use after combat injury in iraq and post-traumatic stress disorder. N Engl J Med Overseas Ed 2010;362:110-7.

2 Cross JD, Ficke JR, Hsu JR, et al. Battlefield orthopaedic injuries cause the majority of long-term disabilities. J Am Acad Orthop Surg 2011;19 Suppl 1:S1.S7.

3 Nikolajsen L, Ilkjaer S, Krøner K, et al. The influence of preamputation pain on postamputation stump and phantom pain. Pain 1997;72:393-405.

4 Otis JD, Keane TM, Kerns RD. An examination of the relationship between chronic pain and post-traumatic stress disorder. J Rehabil Res Dev 2003;40:397-405.

5 Smith JE, Russell R, Mahoney PF, et al. What is the ideal pre-hospital analgesic? A questionnaire study. J R Army Med Corps 2009;155:44-6.

6 Gaunt C, Gill J, Aldington D. British military use of morphine: a historical review. J $R$ Army Med Corps 2009;155:46-9.

7 Hoffman RS, Goldfrank LR. The poisoned patient with altered consciousness. Controversies in the use of a 'coma cocktail'. JAMA 1995;274:562-9.

8 Beecher HK. Delayed morphine poisoning in battle casualties. J Am Med Assoc 1944;124:1193-4.

9 Boyer EW. Management of opioid analgesic overdose. N Engl J Med 2012;367:146-55.

10 Aldington D, Jagdish S. The fentanyl 'lozenge' story: from books to battlefield. J $R$ Army Med Corps 2014;160:102-4.

11 Rogers E, Wright C, King P. Fentanyl lozenge story part 2: from military procurement to package. J R Army Med Corps 2018-jramc-2017-000901--2015.

12 Islamic Republic of Afghanistan Ministry of Counter Narcotics. Afghanistan opium survey. Afghanistan: Islamic Republic of Afghanistan Ministry of Counter Narcotics, 2014. (accessed 11 Nov 2017).

13 Islamic Republic of Afghanistan Ministry of Counter Narcotics. Afghanistan Drug Report 2012. Afghanistan: Islamic Republic of Afghanistan Ministry of Counter Narcotics, 2012. (accessed 11 Nov 2017).

14 Park C, Roberts D, Aldington D, et al. Prehospital analgesia: systematic review of evidence. J R Army Med Corps 2010;156:S295-300.

15 Benov A, Salas MM, Nakar H, et al. Battlefield pain management: a view of 17 years in Israel Defense Forces. J Trauma Acute Care Surg 2017:83:150-5.

16 Petz LN, Tyner S, Barnard E, et al. Prehospital and en route analgesic use in the combat setting: a prospectively designed, multicenter, observational study. Mil Med 2015; 180:14-18

17 Galvagno SM, Mabry RL, Maddry J, et al. Measuring MEDEVAC: metrics for performance improvement. J Trauma Acute Care Surg 2018;84:150-6.

18 Wedmore IS, Kotwal RS, McManus JG, et al. Safety and efficacy of oral transmucosal fentanyl citrate for prehospital pain control on the battlefield. J Trauma Acute Care Surg 2012;73:S490-S495.

19 Shackelford SA, Fowler M, Schultz K, et al. Prehospital pain medication use by U.S. Forces in Afghanistan. Mil Med 2015;180:304-9.

20 Buckenmaier CC, Rupprecht C, McKnight G, et al. Pain following battlefield injury and evacuation: a survey of 110 casualties from the wars in Iraq and Afghanistan. Pain Med 2009:10:1487-96.

21 Smith MD, Wang Y, Cudnik M, et al. The effectiveness and adverse events of morphine versus fentanyl on a physician-staffed helicopter. J Emerg Med 2012;43:69-75.

22 Davey CM, Mieville KE, Simpson R, et al. A proposed model for improving battlefield analgesia training: post-graduate medical officer pain management day. J R Army Med Corps 2012;158:190-3. 